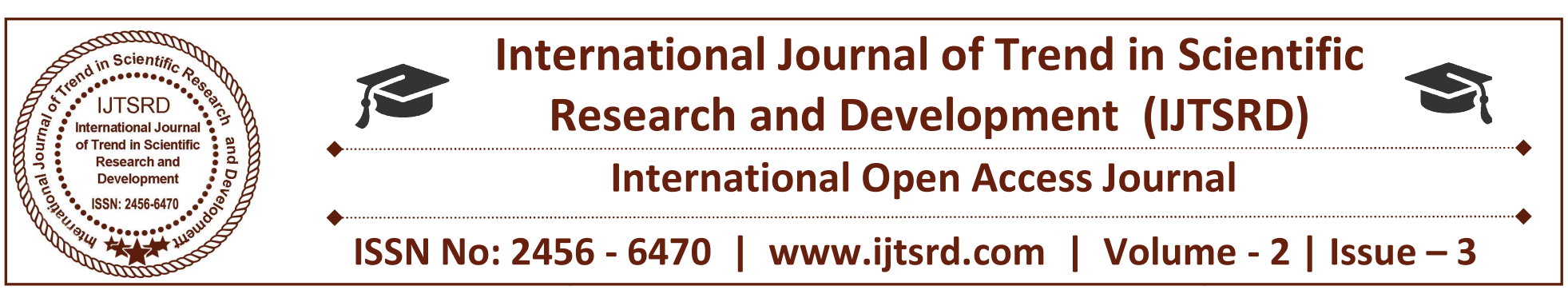

\title{
Characterization of $\mathrm{Al} / \mathrm{WC} / \mathrm{Fly}$ ash Metal Matrix Composites
}

\author{
Nithin K \\ Assistant Professor, Kelappaji College of Agricultural \\ Engineering and Technology, Tavanur, Kerala, India
}

\section{ABSTRACT}

Metal matrix composites are formed by combination of two or more materials (at least one of the materials is metal) having dissimilar characteristics. In this present investigation, aluminium (Al 6061) as base matrix metal and tungsten carbide (WC) particulate, fly ash as reinforcements. Fabrication of MMCs was done by stir-casting process. The Tungsten Carbide particulate was added in proportions of $1 \%, 2 \%$, and $3 \%$ and Fly ash was added in proportions of $2 \%, 4 \%$, and $6 \%$ on mass fraction basis to the molten metal. The different combination sets of composites were prepared. Mechanical properties like tensile strength and hardness were studied for both reinforced and unreinforced Al 6061 samples. Microstructure examination was carried by using Scanning Electron Microscope (SEM) to obtain the distribution of tungsten carbide particulate and fly ash in base matrix. From the results, it was found that the tensile strength and the hardness of the prepared metal matrix composites increased with increase in tungsten carbide and fly ash content. The Scanning Electron Micrographs of the samples indicated uniform distribution of tungsten carbide and fly ash particles in the base matrix without voids before testing and with voids after testing.

Keywords: Aluminium metal matrix composite, Tungsten Carbide, Fly ash, Stir-casting, Mechanical properties, SEM

\section{INTRODUCTION}

Metal matrix composites (MMCs), like most composite materials, provide enhanced properties over monolithic materials, such as higher strength, stiffness, hardness and weight savings. Aluminium based metal matrix composites are concentrating more for engineering applications since it is the class of light weight and high performance aluminium centric materials system.

Al6061 is the form of aluminium alloy containing magnesium and silicon as major alloying elements, commonly used for aerospace, marine applications, cycling and automotive applications and to make gas cylinders. Al6061 is heat treatable, can be easily welded, with very good corrosion resistance and finishing characteristics. It has medium strength, hardness.

Particulate composites are widely used in composites development because they are cheap and of manufacturing ease. Particulate reinforced MMCs have recently found special interest because of their specific strength and specific stiffness at room or elevated temperatures. Ceramic particles or fibers are commonly used as reinforcement. The basic reason of metals reinforced with hard ceramic particles or fibers are improved properties than its original material like strength, stiffness, wear resistance etc. It can also improve strength to weight ratio of the composites.

Fabrication of composites is commonly done by the stir- casting among the different processing techniques available, because it is simplest and cheapest form, references [7][8][9].

In recent days, considerable work has been done on tungsten carbide reinforced metal matrix composites as well as fly ash reinforced metal matrix composites.

The tungsten carbide is used as reinforcement in Al6061 matrix composites with different weight percentages, references [1][2][3]. The fabrication is done by stir casting process, reference [2]. It was found that increasing the WC content within the 
matrix material, resulted in significant improvement in mechanical properties like hardness, tensile strength. Density also increases with increase in tungsten carbide content, in reference [1]. Wear resistance increases with increase in WC content, in reference [2].

In references [4][5][6], fly ash is used as reinforcement in aluminium composites. Fabrication is done by stir-casting method. It was found that as increase in fly ash content, resulted in increase in tensile strength, hardness and decrease in density.

\section{EXPERIMENTAL DETAILS}

Aluminium alloy (A16061) is taken as base matrix metal, tungsten carbide (WC) particulate of $2-3 \mu \mathrm{m}$ size and fly ash are taken as reinforcements. WC was taken in $1 \%, 2 \%$, and $3 \%$ on mass fraction and fly ash was taken $2 \%, 4 \%$, and $6 \%$ on mass fraction.

\section{A. Composite Fabrication}

Fabrication of composites is done by stir-casting method. Al6061 alloy ingots are kept in crucible and melt in electric resistance furnace at $850^{\circ} \mathrm{C}$. The melt was degassed by adding solid dry hexachloroethane $\left(\mathrm{C}_{2} \mathrm{Cl}_{6}\right)$, called degasser. The stirring setup is brought near the furnace, stirrer is dipped inside crucible and stirred at $500 \mathrm{rpm}$. The calculated amount of the preheated reinforcement particles of WC and fly ash were added slowly into the melt. As the impeller rotates it generates a vortex that draws the reinforcement particle into the melt from the surface. The stirring action was carried out about $10-15 \mathrm{~min}$. After by removing stirrer setup, the mixed melt is poured to the required preheated metallic mould of $22 \mathrm{~mm}$ diameter and $220 \mathrm{~mm}$ length. The molten metal is made to solidify and the prepared casting is removed from the mould.

The casted composites were sectioned and made to prepare tensile testing, hardness and dry wear testing specimens as per ASTM standards.

\section{B. Testing for Mechanical Properties}

The specimens were prepared and tensile testing was carried out as per ASTM E8 standard in computerized UTM. Hardness testing by Brinell Hardness tester was carried to the prepared specimen as per ASTM E10 standard, where steel ball indenter of dia. $10 \mathrm{~mm}$ and applied load of $500 \mathrm{kgf}$ were used.

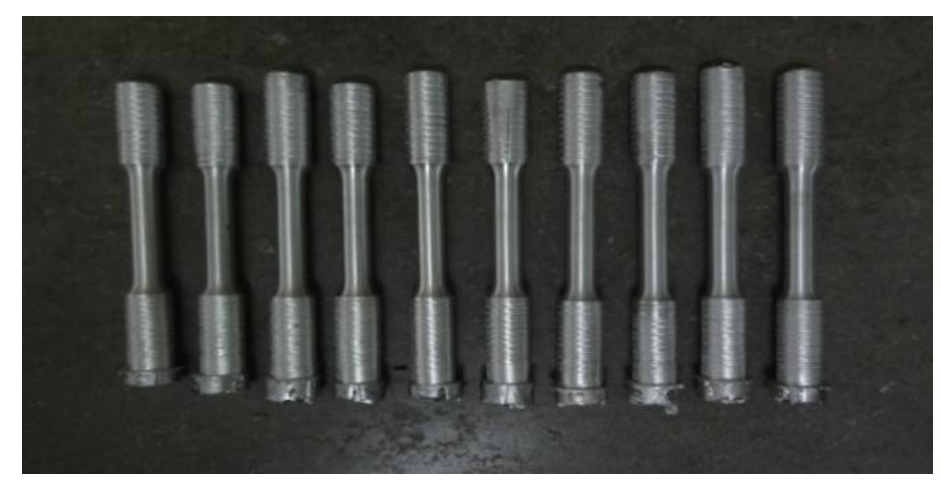

Fig. 1: Tensile test specimens

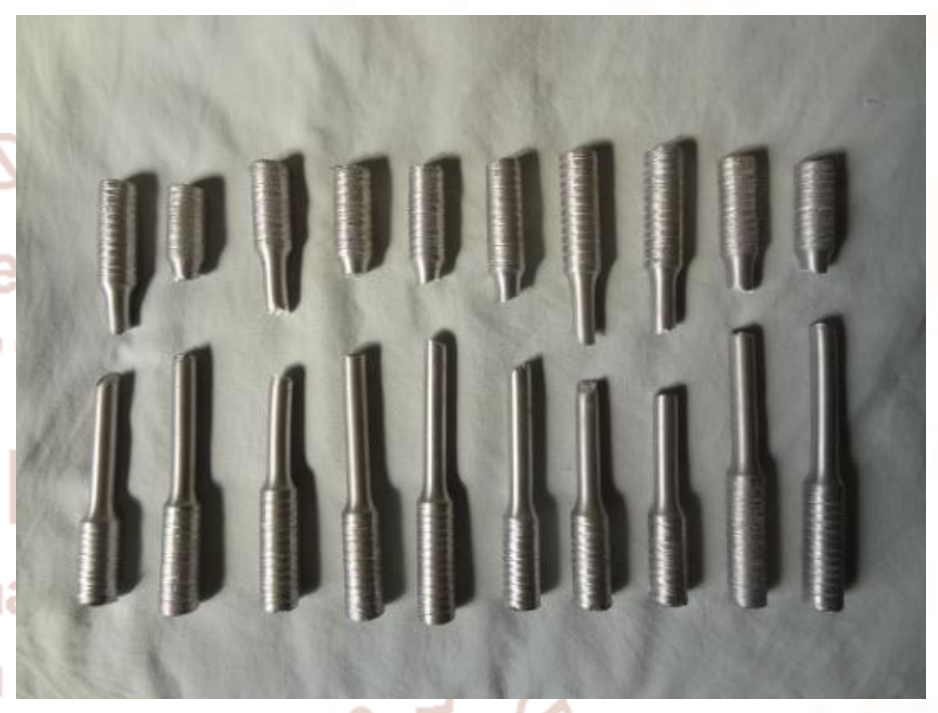

Fig. 2: Tensile test specimens after test

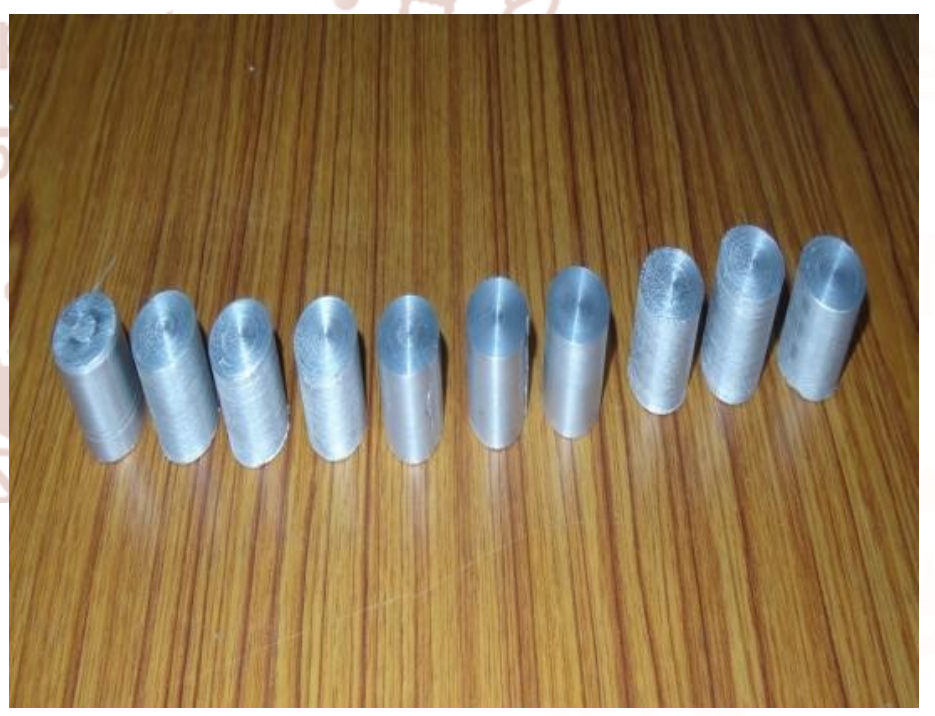

Fig. 3: Brinell Hardness test specimens 


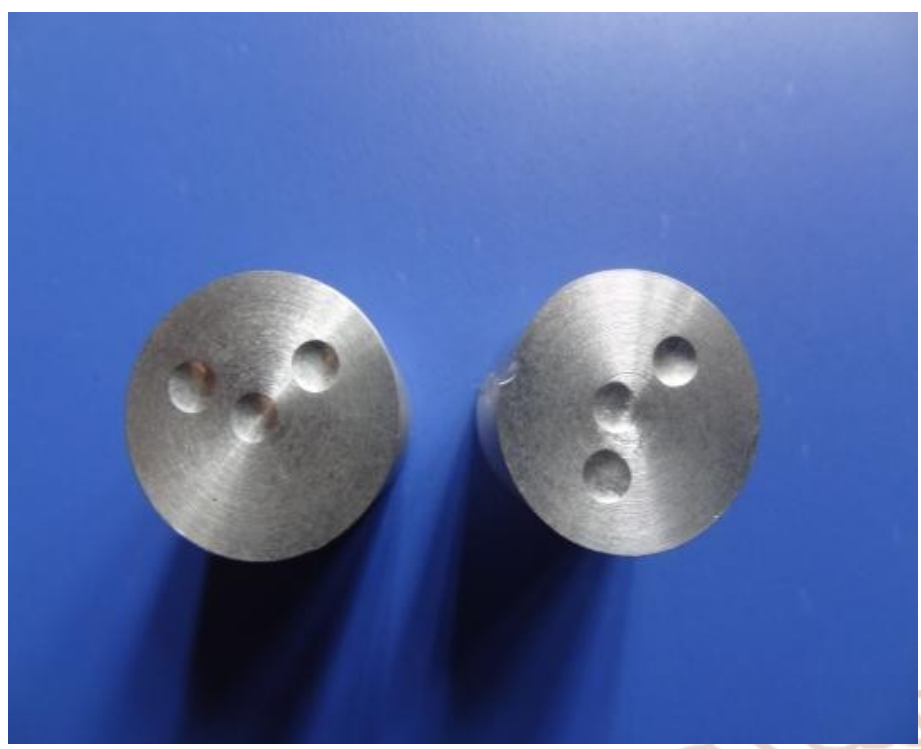

III. RESULTS AND DISCUSSION

\section{A. Tensile properties}

TABLE I. shows the variation of tensile strength of the composites with the different weight fractions of tungsten carbide and fly ash particles. It can be noted that the tensile strength increased with an increase in the weight percentage of tungsten carbide and fly ash. This is due to the reinforcement particles acts as barrier to dislocation movement in microstructure.

Fig. 4. Brinell Hardness tested specimens

TABLE I: THE TENSILE TEST RESULTS

\begin{tabular}{|c|c|c|c|c|}
\hline Serial No. & Reinforcement content ( $\%)$ & $\begin{array}{l}\text { Peak load } \\
(\mathrm{KN})\end{array}$ & $\begin{array}{ll}\text { Tensile } & \text { Strength } \\
\left(\mathrm{N} / \mathrm{mm}^{2}\right) & \\
\end{array}$ & $\begin{array}{c}\% \frac{1}{0} \\
\text { Elongation }\end{array}$ \\
\hline 1 & WC- $0 \%$ and flyash- $0 \%$ & $\square .16 .41$ & 130.778 & 16.02 \\
\hline 2 & WC- $1 \%$ and flyash- $2 \%$ & 16.32 & 132.349 & 09.96 \\
\hline 3 & WC- $1 \%$ and flyash- $4 \%$ atci & Onat 18.05 urr & 148.036 & 08.90 \\
\hline 4 & WC- $1 \%$ and flyash- $6 \%$ & ing 17.60 & 148.598 & 07.48 \\
\hline 5 & WC- $2 \%$ and flyash $-2 \%$ & 18.40 & 150.906 & 06.84 \\
\hline 6 & WC- $2 \%$ and flyash- $4 \%$ & 21.05 & 167.756 & 05.28 \\
\hline 7 & WC- $2 \%$ and flyash- $6 \%$ eVe & 101020.56 & 169.430 & 04.90 \\
\hline 8 & WC-3\% and flyash- $2 \%$ & 21.15 & 171.241 & 04.54 \\
\hline 9 & WC-3\% and flyash-4\% & 445020.580 & 173.776 & 03.74 \\
\hline 10 & WC-3\% and flyash- $6 \%$ & 21.98 & 179.110 & 02.66 \\
\hline
\end{tabular}

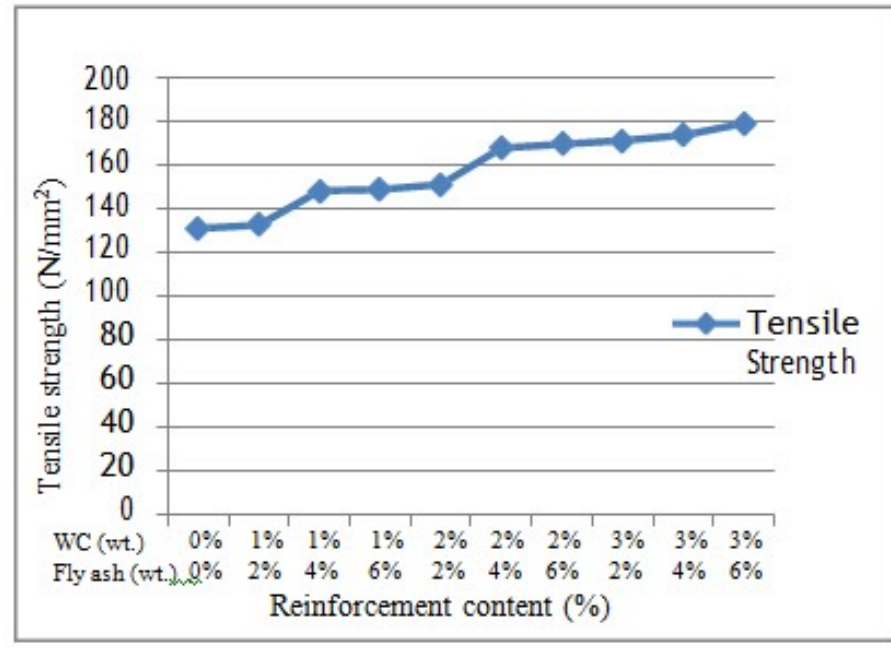

Fig. 5: Graph of tensile strength v/s reinforcement content (\%) with Al6061

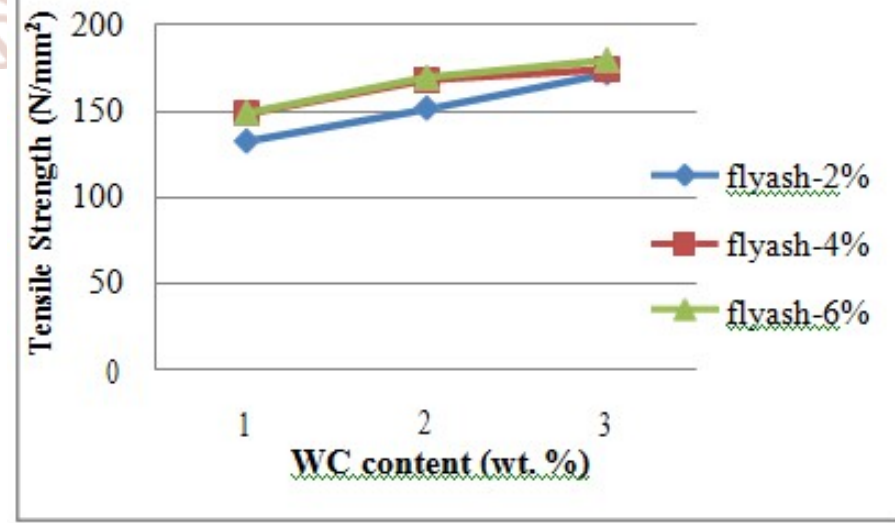

Fig. 6: Graph of tensile strength v/s WC content (wt. \%) with varying fly ash content 
International Journal of Trend in Scientific Research and Development (IJTSRD) ISSN: 2456-6470

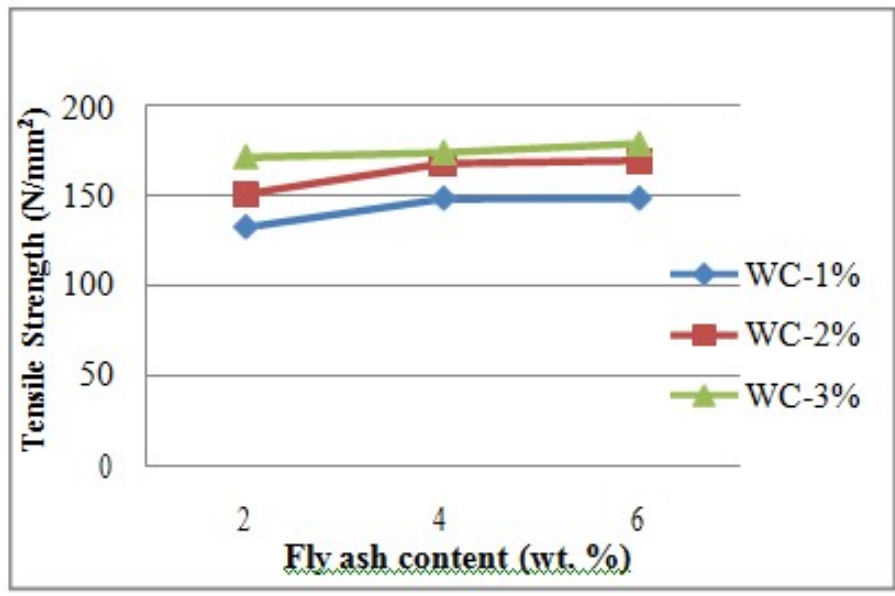

\section{B. Hardness}

TABLE II shows the variation of hardness of the composites with different weight fractions of tungsten carbide and fly ash particles. It can be noted that the hardness of the composite increased with the increase in weight fraction of the fly ash particles.

Fig. 7. Graph of tensile strength v/s fly ash content (wt. \%) with varying $\mathrm{WC}$ content

TABLE II: HARDNESS TEST RESULTS

\begin{tabular}{|c|c|c|c|c|c|}
\hline SI No & $\begin{array}{l}\text { Reinforcement content } \\
\qquad(\%)\end{array}$ & $\begin{array}{l}\text { Ball diameter, } \\
\text { D (mm) }\end{array}$ & $\begin{array}{l}\text { Load, P } \\
\text { (Kgf) }\end{array}$ & $\begin{array}{l}\text { Mean diameter of } \\
\text { indentation } \\
{ }_{, d^{\text {ee }}}(\mathrm{mm})\end{array}$ & $\begin{array}{c}\text { Brinell } \\
\text { Hardness } \\
\text { Number, BHN }\end{array}$ \\
\hline 1 & WC- $0 \%$ and flyash- $0 \%$ & 10 & 500 & 4.30 & 32.92 \\
\hline 2 & WC- $1 \%$ and flyash-2\% & 10 & 500 & 4.21 & 34.35 \\
\hline 3 & WC- $1 \%$ and flyash- $4 \%$ & -10 & 500 & 4.15 & 35.30 \\
\hline 4 & WC- $1 \%$ and flyash- $6 \%$ & 10 & 500 & 4.00 & 38.13 \\
\hline 5 & WC- $2 \%$ and flyash- $2 \%$ & 10 & 500 & 3.90 & 40.20 \\
\hline 6 & $\mathrm{WC}-2 \%$ and flyash- $4 \%$ & 10 & 500 & 3.70 & 44.85 \\
\hline 7 & WC-2\% and flyash-6\% & 10 & $56=500$ & 3.57 & 48.31 \\
\hline 8 & WC-3\% and flyash-2\% & 10 & 500 & 340 & 50.62 \\
\hline 9 & WC-3\% and flyash-4\% & 10 & 500 & 3.40 & 53.43 \\
\hline 10 & WC-3\% and flyash- $6 \%$ & 10 & 500 & 3.37 & 54.42 \\
\hline
\end{tabular}

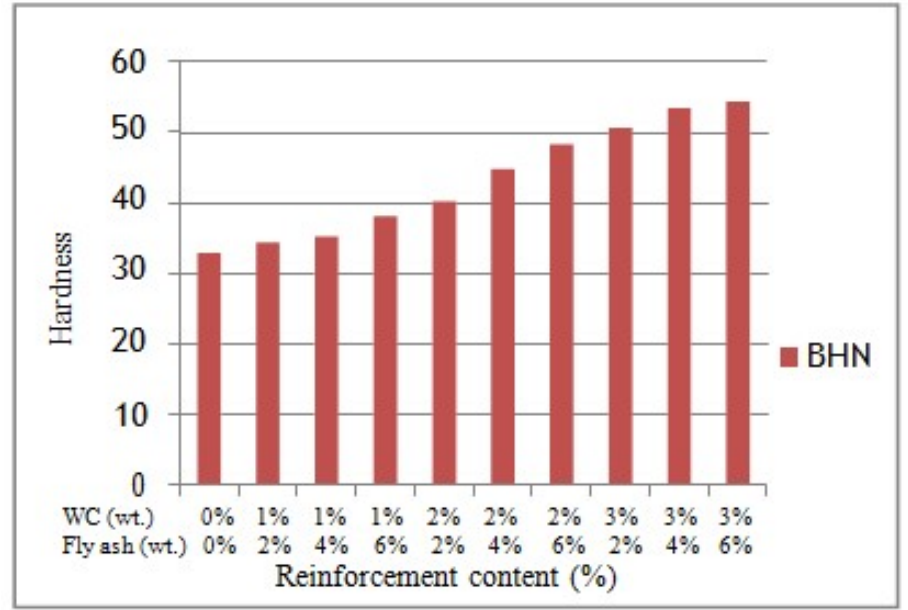

Fig 8: Graph of Hardness (BHN) v/s reinforcement content (wt. \%) with Al6061

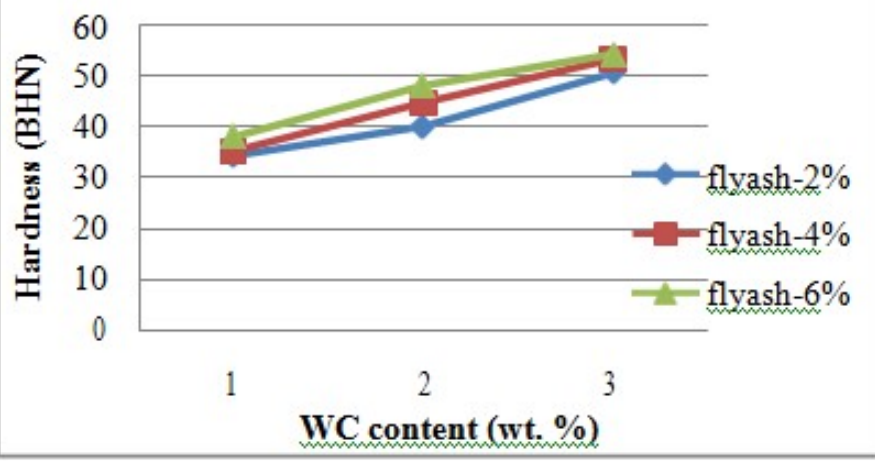

Fig. 9: Graph of Hardness (BHN) v/s WC content (wt. \%) with varying fly ash content 
International Journal of Trend in Scientific Research and Development (IJTSRD) ISSN: 2456-6470

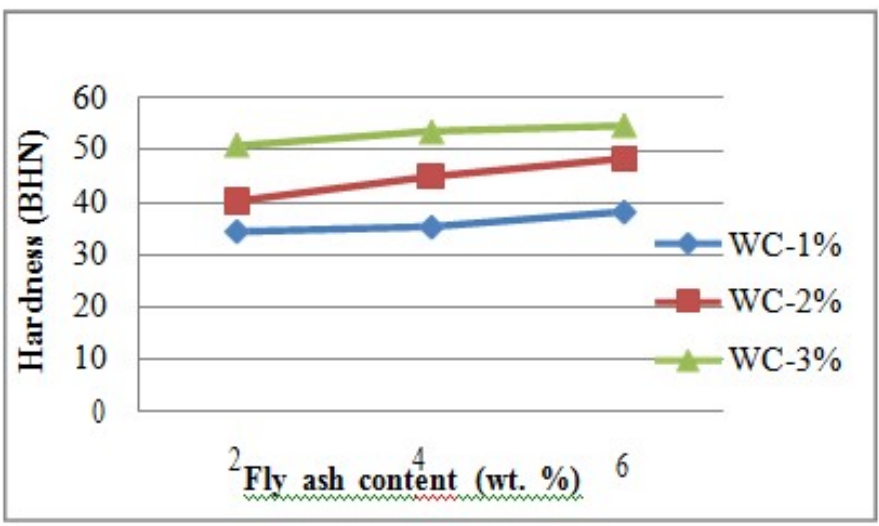

Fig. 10: Graph of Hardness (BHN) v/s fly ash content (wt. \%) with varying $\mathrm{WC}$ content

\section{Microstructure}

As the microstructure plays an important role in the overall performance of a composite and the physical properties depend on the microstructure, reinforcement particle size, shape and distribution in the alloy, prepared samples were examined using a Scanning Electron Microscope (SEM) to study the distribution pattern of tungsten carbide and fly ash in the matrix. The micrographs of composites before and after testing can be seen below.

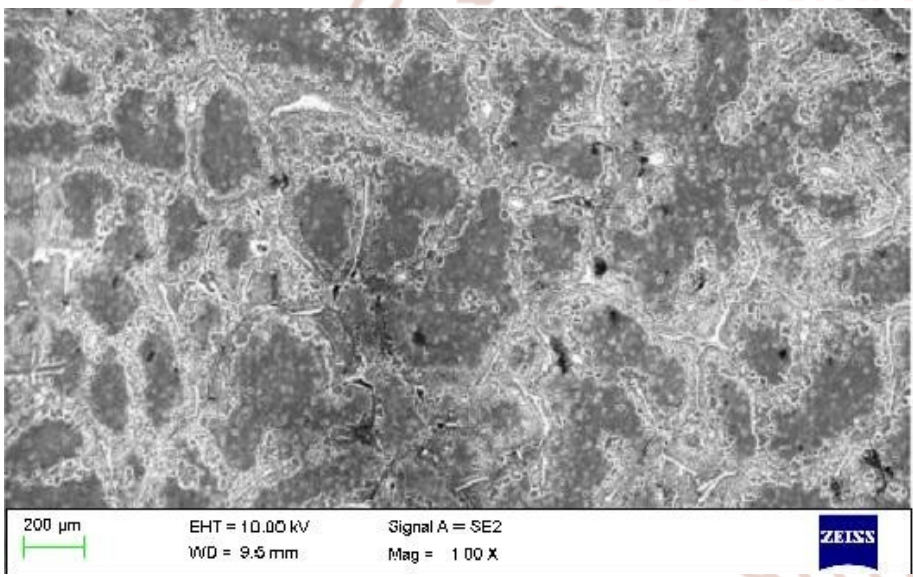

Fig. 11: SEM micrograph of Al6061+WC1\%+fly ash $2 \%$.

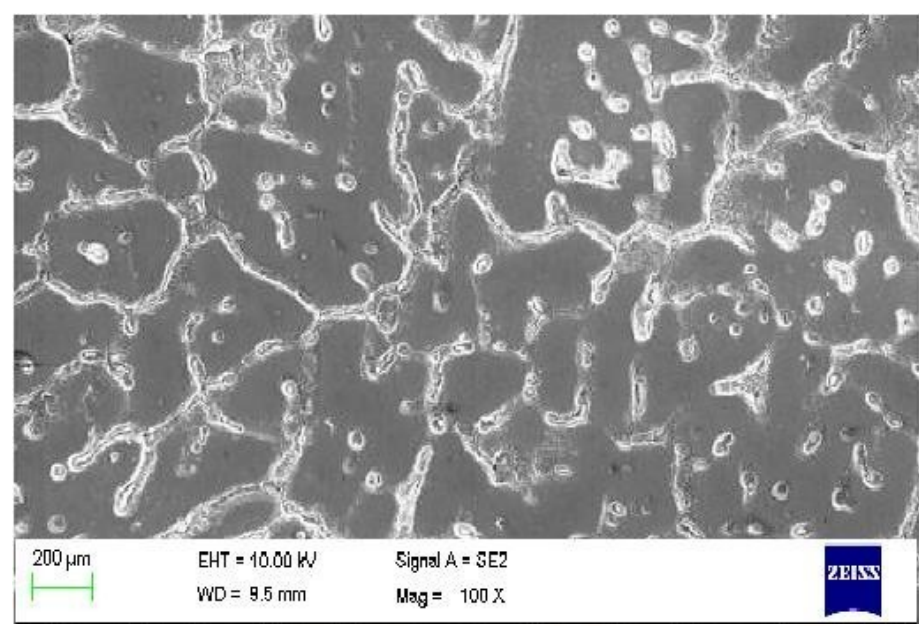

Fig. 12: SEM micrograph of Al6061+WC2\%+fly ash $2 \%$.

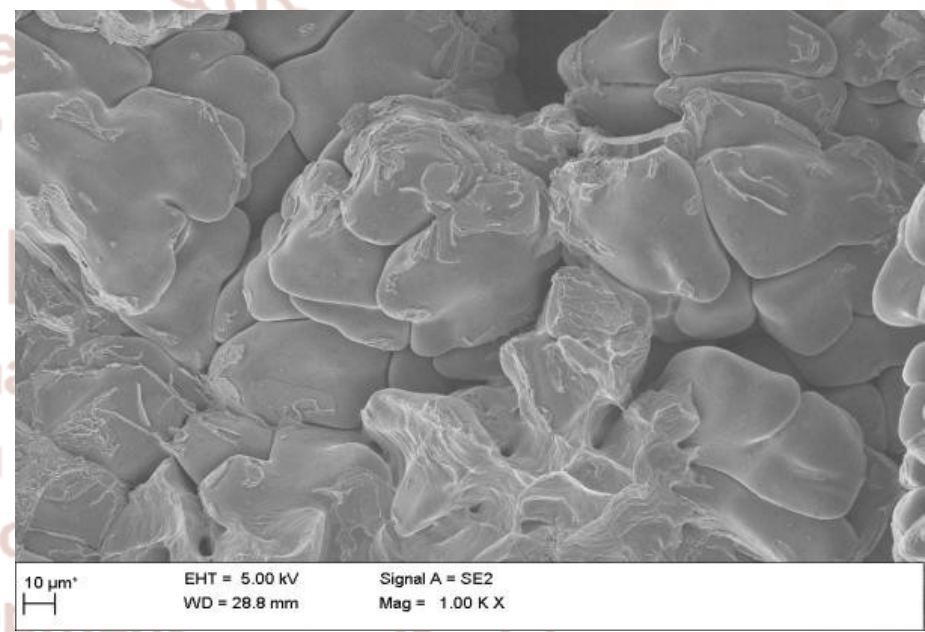

Fig 13: SEM micrograph of tensile fractured surface of Al6061+WC 1\%+fly ash 2\%.

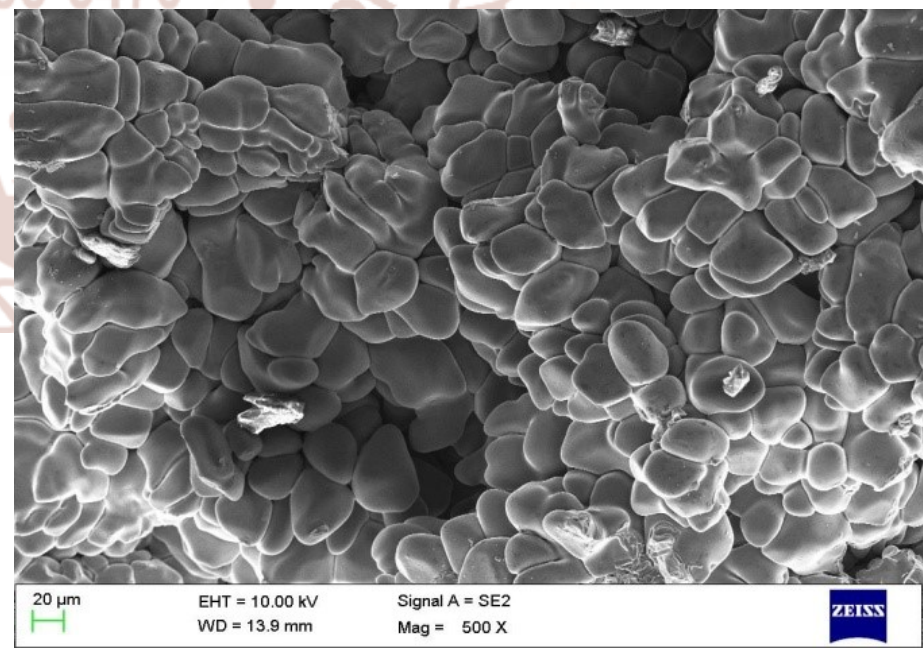

Fig 14: SEM micrograph of tensile fractured surface of Al6061+WC 2\%+fly ash 4\%. 


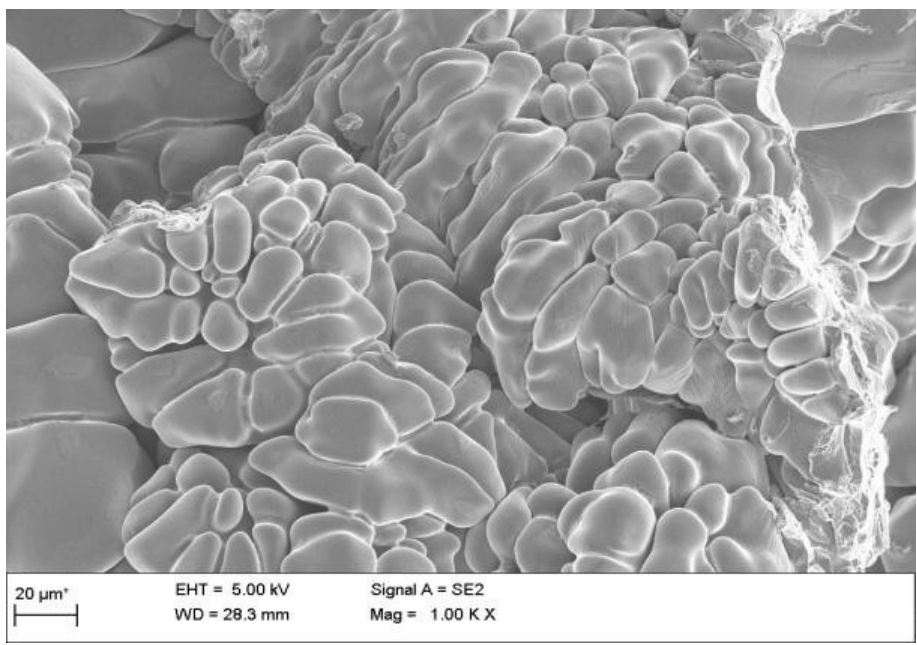

Fig. 15: SEM micrograph of tensile fractured surface of Al6061+WC 3\%+fly ash $6 \%$.

\section{CONCLUSION}

A16061 matrix composites were easily and economically fabricated by stir-casting method with tungsten carbide and fly ash particulates as reinforcements. The mechanical properties are enhanced.

From the tensile test results, it is found that the tensile strength increased, as reinforcement content in weight percentage increases, Increase in reinforcement content in matrix, decreased in ductility of composites.

From brinell hardness test results, increase in reinforcement content in matrix, there is increase in hardness of composites.

The enhancement effect of tungsten carbide reinforcement is more compared to fly ash reinforcement in tensile strength and hardness properties.

From SEM micrograph studies, equal distribution of reinforcement content (tungsten carbide and fly ash particulates) in Al6061 matrix composites without any voids formation. In tensile fractured surface, observed that formation of voids observed. As reinforcement content increases, the size of the voids are decreased, indicating less ductility.

\section{REFERENCES}

1. S Jerry Andrews Fabian, B. Selvam, "Densification behaviour of Aluminium reinforced with Tungsten Carbide particulate
Metal Matrix Composite processed by $\mathrm{P} / \mathrm{M}$ ", IOSR Journal of Mechanical and Civil Engineering (IOSR-JMCE), PP 24-29.

2. Amarnath.G, K.V. Sharma, "Microstructure and tribological properties of nanoparticulate WC/Al metal matrix composites", International journal of mechanical engineering and technology (ijmet), Volume 4, Issue 2, pp. 178-188 March - April 2013.

3. Hari Prasada Rao Pydi, Balamurugan Adhithan, A.Syed Bava Bakrudeen ,"Microstructure Exploration of the Aluminum-Tungsten Carbide Composite with different Manufacturing circumstances", International Journal of Soft Computing and Engineering (IJSCE) ISSN: 22312307, Volume-2, Issue-6, January 2013.

4. Arun Kumar M. B, R. P. Swamy, "Evaluation of mechanical properties of Al6061, Flyash and Eglass fiber reinforced hybrid Metal matrix composites", ARPN Journal of Engineering and Applied Sciences, VOL. 6, NO. 5, pp. 40-44, May 2011.

5. Deepak Singla, S.R. Mediratta, "Evaluation of mechanical properties of Al 7075-fly ash composite material", International Journal of Innovative Research in Science, Engineering and Technology, Vol. 2, Issue 4, April 2013.

6. H.C. Anilkumar, H.S. Hebbar, K.S. Ravishankar, "Mechanical properties of fly ash reinforced aluminium alloy (al6061) composites", International Journal of Mechanical and Materials Engineering (IJMME), Vol.6, No.1, 41-45, 2011.

7. Lloyd D.J. and Brotzen F.R., "Particle reinforced aluminium and $\mathrm{Mg}$ matrix composites" Int. Mater. Rev; 39,1-39, 1994.

8. Rajeshkumar Gangaram Bhandare, Parshuram M. Sonawane, "Preparation of Aluminium Matrix Composite by Using Stir Casting Method", International Journal of Engineering and Advanced Technology (IJEAT) ISSN: 2249 8958, Volume-3, Issue-2, December 2013.

9. G.N.Lokesh, M.Ramachandra, K.V.Mahendra, T.Sreenith, "Effect of Hardness, Tensile and Wear Behavior of Al-4.5wt $\% \mathrm{Cu}$ Alloy/Flyash $/ \mathrm{SiC}$ Metal Matrix Composites", International Journal of Modern Engineering Research (IJMER), Vol.3, Issue.1, pp-381-385, Jan-Feb. 2013. 